BNL-114114-2017-JA

\title{
Visualization of Structural Evolution and Phase Distribution of Lithium Vanadium Oxide (Li1.1V3O8) Electrode via Operando and In-situ Energy Dispersive X-ray Diffraction Technique
}

\author{
Q. Zhang, A. M. Bruck, D. C. Bock, J. Li, V. Sarbada, R. Hull,
} E. A. Stach, K. J. Takeuchi, E. S. Takeuchi, and A. C. Marschilok

Submitted to Physical Chemistry Chemical Physics

June 7, 2017

\begin{abstract}
Energy and Photon Sciences Directorate
Brookhaven National Laboratory
\end{abstract}

\author{
U.S. Department of Energy \\ USDOE Office of Science (SC), \\ Basic Energy Sciences (BES) (SC-22)
}

\footnotetext{
Notice: This manuscript has been co-authored by employees of Brookhaven Science Associates, LLC under Contract No. DE-SC0012704 with the U.S. Department of Energy. The publisher by accepting the manuscript for publication acknowledges that the United States Government retains a non-exclusive, paid-up, irrevocable, world-wide license to publish or reproduce the published form of this manuscript, or allow others to do so, for United States Government purposes.
} 


\section{DISCLAIMER}

This report was prepared as an account of work sponsored by an agency of the United States Government. Neither the United States Government nor any agency thereof, nor any of their employees, nor any of their contractors, subcontractors, or their employees, makes any warranty, express or implied, or assumes any legal liability or responsibility for the accuracy, completeness, or any third party's use or the results of such use of any information, apparatus, product, or process disclosed, or represents that its use would not infringe privately owned rights. Reference herein to any specific commercial product, process, or service by trade name, trademark, manufacturer, or otherwise, does not necessarily constitute or imply its endorsement, recommendation, or favoring by the United States Government or any agency thereof or its contractors or subcontractors. The views and opinions of authors expressed herein do not necessarily state or reflect those of the United States Government or any agency thereof. 


\section{Journal Name}

\section{ARTICLE}

\section{Visualization of Structural Evolution and Phase Distribution of Lithium Vanadium Oxide $\left(\mathrm{Li}_{1.1} \mathrm{~V}_{3} \mathrm{O}_{8}\right)$ Electrode via Operando and In-situ Energy Dispersive X-ray Diffraction Technique}

Received 00th January 20xx, Accepted 00th January 20xx

DOI: $10.1039 / \times 0 \times x 00000 x$

www.rsc.org/
Qing Zhang, ${ }^{a}$ Andrea M. Bruck, ${ }^{b}$ David C. Bock, ${ }^{c}$ Jing Li, ${ }^{a}$ Varun Sarbada, ${ }^{d}$ Robert Hull, ${ }^{\text {,e }}$ Eric A. Stach, Kenneth J. Takeuchi, ${ }^{a, b^{*}}$ Esther S. Takeuchi, ${ }^{a, b, c^{*}}$ and Amy C. Marschilok ${ }^{a, b^{*}}$

\section{Introduction}

Vanadium-based compounds are favorable materials for $\mathrm{Li}$ ion batteries due to the possibility of multiple electron transfers per formula unit within a desirable voltage range and thus high energy density. ${ }^{1-10}$ Multiple oxide materials with vanadium redox centers have been studied as electrode materials for $\mathrm{Li}$ ion batteries, including $\mathrm{Na}_{x} \mathrm{~V}_{6} \mathrm{O}_{15},{ }^{11} \mathrm{~V}_{2} \mathrm{O}_{5},{ }^{12} \mathrm{Na}_{x} \mathrm{~V}_{2} \mathrm{O}_{5},{ }^{13}, 14$ $\mathrm{Na}_{\mathrm{x}} \mathrm{V}_{3} \mathrm{O}_{8},{ }^{15} \quad \mathrm{Na}_{\mathrm{x}} \mathrm{V}_{6} \mathrm{O}_{15},{ }^{11} \quad \mathrm{Li}_{\mathrm{x}} \mathrm{V}_{2} \mathrm{O}_{5},{ }^{16} \mathrm{~V}_{6} \mathrm{O}_{13},{ }^{17}$ and $\mathrm{Li}_{1+\mathrm{x}} \mathrm{V}_{3} \mathrm{O}_{8}{ }^{18}$ Among these materials, the monoclinic layered $\mathrm{Li}_{1+n} \mathrm{~V}_{3} \mathrm{O}_{8}(\mathrm{n}=0$ 0.2) (LVO) is especially promising as it exhibits a high theoretical capacity of $362 \mathrm{mAh} \cdot \mathrm{g}^{-1}$, and good rate

\footnotetext{
${ }^{a .}$ Department of Materials Science and Engineering, Stony Brook University, Stony Brook, NY 11794

${ }^{b .}$ Department of Chemistry, Stony Brook University, Stony Brook, NY 11794

c. Energy Sciences Directorate, Brookhaven National Laboratory, Upton, NY 11973

${ }^{d .}$ Department of Materials Science and Engineering, Rensselaer Polytechnic Institute, Troy, NY 12180

e. Center for Materials, Devices, and Integrated Systems, Rensselaer Polytechnic Institute, Troy, NY 12180

f. Center for Functional Nanomaterials, Brookhaven National Laboratory, NY 11973

*corresponding authors: (KJT) kenneth.takeuchi.1@stonybrook.edu, (EST)

esther.takeuchi@stonybrook.edu, (ACM)amy.marschilok@stonybrook.edu
}

capability. ${ }^{19,20}$ Prior research efforts have centered on modification of preparation approaches to improve the functional capacity of this material. ${ }^{18,}{ }^{20-29}$ Preparation conditions including annealing temperature have a strong impact on the characteristics of the product and therefore impact the electrochemical outcomes. LVO annealed at higher temperatures $\left(500-550^{\circ} \mathrm{C}\right)$ usually exhibits a lower surface area and higher crystallinity compared to the material annealed at moderate temperature $\left(300^{\circ} \mathrm{C}\right) .^{24}$ The more crystallized LVO prepared at higher temperature usually delivers less capacity on initial discharge with better capacity retention over extended cycling compared to the less crystallized material prepared at lower temperature. ${ }^{24}$ The observed differences in electrochemistry of the materials annealed at different temperatures imply that different lithiation processes are occurring and necessitate a structural examination of the material in the lithiated state.

The structure of LVO can be viewed as a stack of $\mathrm{V}_{3} \mathrm{O}_{8}$ sheets held together by $\mathrm{Li}^{+}$ions residing in the interlayer positions. ${ }^{30}$ Major phase transitions during lithiation include the transition of layered phase $\alpha$ from the starting Li-poor to Li-rich form, with an approximate composition of $\mathrm{Li}_{2.5} \mathrm{~V}_{3} \mathrm{O}_{8}$, and the transformation from Li-rich $\alpha$ to defected rock-salt phase $\beta$, 
with an approximate composition in the range of $\mathrm{Li}_{3.5} \mathrm{~V}_{3} \mathrm{O}_{8}$ Li4V3O8, as shown in Equations (1-3) below.

$L i_{1.1} V_{3} O_{8}(\alpha)+1.4 e^{-} \rightleftharpoons L_{2.5} V_{3} O_{8}(\alpha)$

$L i_{2.5} V_{3} O_{8}(\alpha)+1.0 e^{-}\left(\right.$or $\left.1.5 e^{-}\right) \rightleftharpoons L i_{3.5} V_{3} O_{8}\left(\right.$ or $\left.L i_{4.0} V_{3} O_{8}\right)(\beta)$

$L i_{3.5} V_{3} O_{8}\left(\right.$ or $\left.L i_{4.0} V_{3} O_{8}\right)(\beta)+1.5 e^{-}\left(\right.$or $\left.1.0 e^{-}\right) \rightleftharpoons L i_{5} V_{3} O_{8}(\beta)$

Diffraction and Rietveld method structural refinement were performed on chemically lithiated $\mathrm{LVO}$ materials, $\mathrm{Li}_{2.7} \mathrm{~V}_{3} \mathrm{O}_{8}$ and $\mathrm{Li}_{4.8} \mathrm{~V}_{3} \mathrm{O}_{8}$, designated as Li-rich $\alpha$ and $\beta$ phase materials respectively. ${ }^{31}$ The analysis indicated that Li-rich $\alpha$ maintains the same $\mathrm{V}_{3} \mathrm{O}_{8}$ layers as the starting Li-poor $\alpha$, with an elongated $b$-axis and shortened $a$-axis to accommodate additional $\mathrm{Li}$. The $\beta$ structure with higher Li concentration has an even longer $b$ axis and shorter $a$ axis, and upon transformation from $\alpha$ to $\beta$, the $\mathrm{V}$ and $\mathrm{O}$ atoms undergo minor movements to allow the structure to accommodate more $\mathrm{Li}^{31,}$ 32

In-situ and ex-situ angle dispersive x-ray diffraction (ADXRD) techniques have been employed to study the phase transformations of LVO during the electrochemical de(lithiation) process. ${ }^{19,} 33,34$ An in-situ ADXRD measurement of $\mathrm{Li}_{1.1} \mathrm{~V}_{3} \mathrm{O}_{8}$ during de(lithiation) in combination with density functional theory (DFT) calculations for the relative stabilities of the $\alpha$ and $\beta$ phases provided a detailed structure evolution analysis from experimental as well as theoretical perspective. ${ }^{34}$ According to the relative stability of the $\alpha$ and $\beta$ phases calculated by DFT, below a Li concentration of $\mathrm{Li}_{2.5} \mathrm{~V}_{3} \mathrm{O}_{8}$, $\alpha$ was more stable than $\beta$, and $\alpha$ was the dominant phase. The stability of $\alpha$ and $\beta$ became similar at the $\mathrm{Li}_{3.0} \mathrm{~V}_{3} \mathrm{O}_{8}$ lithiation level. Beyond $\mathrm{Li}_{3.5} \mathrm{~V}_{3} \mathrm{O}_{8}, \alpha$ became less stable than $\beta$ and $\beta$ was the dominant phase. The theoretical calculation was validated by the in-situ ADXRD experiment, which revealed that lithiation took place in single phase $\alpha$ up to the Li content of $\mathrm{Li}_{2.5} \mathrm{~V}_{3} \mathrm{O}_{8}$, where $\beta$ phase formed and $\alpha-\beta$ transition started. At $\mathrm{Li}_{3.5} \mathrm{~V}_{3} \mathrm{O}_{8}, \alpha$ phase disappeared and beyond this composition, lithiation was in single $\beta$ phase. The de-lithiation was a reverse process where $\beta$ phase de-lithiated first, followed by $\beta$ - $\alpha$ transition and de-lithiation of single phase $\alpha$ to the starting $\alpha$ phase.

Energy dispersive $x$-ray diffraction (EDXRD) uses high-energy and high-flux $x$-rays which can penetrate the stainless steel housing of an intact battery and achieve spatial resolution of the electrochemical processes at different locations with a functioning cell, avoiding potential issues related to use of a beryllium window such as stack pressure. In addition, operando and in-situ EDXRD measurements eliminate the artifacts associated with removal of electrode material from its native environment and post-treatments, and provide insight into the electrochemical processes which might be different with destructive methods. In an in-situ EDXRD study performed on coin-type $\mathrm{Li} / \mathrm{Ag}_{2} \mathrm{VP}_{2} \mathrm{O}_{8}$ cells, silver formation which was an indicator of reduction of $\mathrm{Ag}_{2} \mathrm{VP}_{2} \mathrm{O}_{8}$ was detected on the $\mathrm{Li}$ anode interface as well as on stainless steel can interface of the cathode in the initial discharge period, and moved throughout the cathode upon further discharge. ${ }^{35}$ It was also discovered that the formation of silver has a ratedependence when conductive additive such as graphite was present in the cathode - silver was more evenly distributed and formed a more effective conducting network when the cell was discharged at slower rate of $C / 1440$, compared to the faster rate of $\mathrm{C} / 168 .{ }^{36}$ EDXRD technique was also used to map the composition of $\mathrm{Zn} / \mathrm{MnO}_{2}$ batteries discharged at different rates and spatially distinguish $\mathrm{Mn}_{3} \mathrm{O}_{4}$ (hausmannite) and $\mathrm{ZnMn}_{2} \mathrm{O}_{4}$ (hetaerolite), which have a d-spacing difference of only $0.04 \AA$. A rate-dependence phenomenon was observed Lower $C$ rates result in formation of hausmannite and hetaerolite, while higher $C$ rates result in hetarolite only. ${ }^{37}$ Using EDXRD, formation time and mechanisms of these spinels can be distinguished. ${ }^{38}$ Similar EDXRD studies have been employed on studying other cathode materials such as $\mathrm{LiMn}_{2} \mathrm{O}_{4}$ and $\mathrm{LiFePO}_{4}$, and identifying the heterogeneous discharge effects at different $C$ rates. ${ }^{39-41}$ In-situ EDXRD study has been carried out on LVO material before, where an undischarged LVO cell and four cells discharged to different lithiation levels at $\mathrm{C} / 150$ were analyzed. ${ }^{42}$ The study reported the phase transformation from Li-poor to Li-rich $\alpha\left(\mathrm{Li}_{2.5} \mathrm{~V}_{3} \mathrm{O}_{8}\right)$, and from Li-rich $\alpha$ to $\beta\left(\mathrm{Li}_{4.1} \mathrm{~V}_{3} \mathrm{O}_{8}\right)$ as the discharged progressed. No localization of phase formation was found throughout the electrode under these measurement conditions. This study prepared the basic foundation for further in-situ and operando studies to elucidate the discharge homogeneity of LVO.

Understanding phase transformation and structural changes accompanying (de)lithiation are of great significance for achieving excellent cyclic stability of electrode materials. All these prior EDXRD studies highlighted the significance of investigating the homogeneity of phase transitions under different electrochemical conditions. From the view point of battery application, the focus of this work is to probe the phase evolution and phase distribution spatially in pelletized LVO electrodes with high mass loading using the tomographic mapping capability of the EDXRD technique. Specifically, we carried out an operando study here to profile the phase transitions during the (de)lithiation processes in real time, identifying the $\alpha-\beta$ transition process and phase localization. Further, LVO materials prepared at different temperatures (LVO300 and LVO500) were pre-discharged at different current rates, and the resulting phase distribution of the discharged electrodes was mapped with in-situ EDXRD. Comparisons between LVO500 and LVO300 were made, and the phase distribution and relative intensity of peaks were analyzed.

\section{Experimental}

Material synthesis and electrochemical cell preparation 

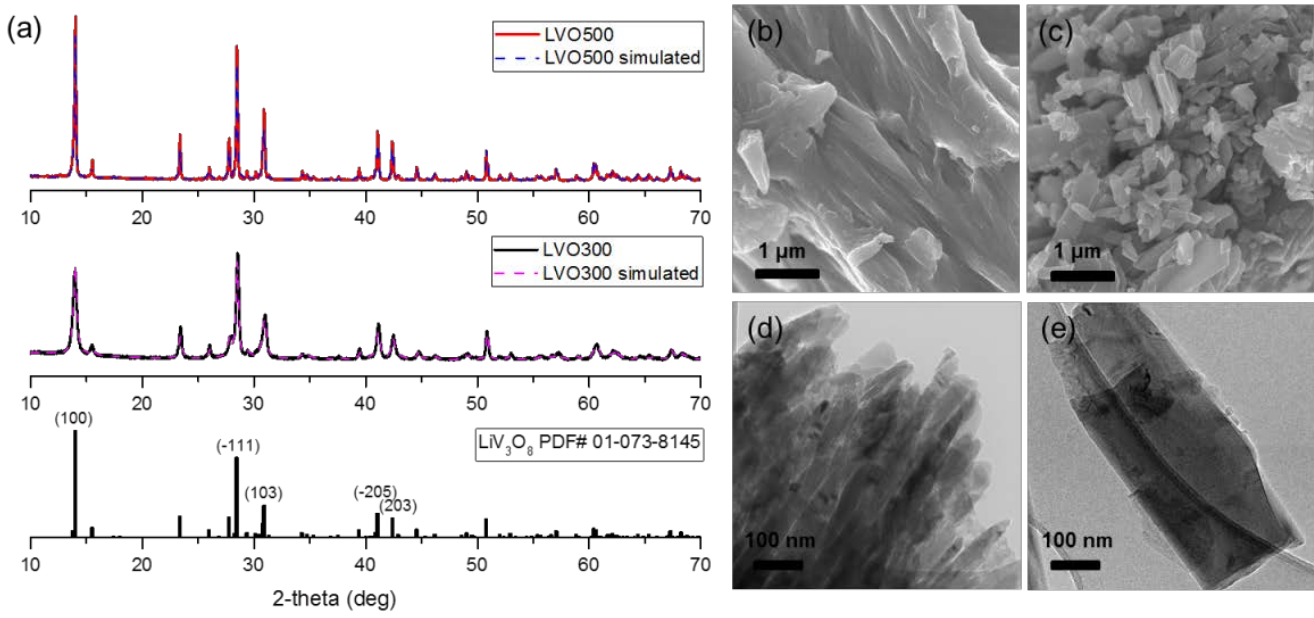

Figure 1 (a) Rietveld refinement analysis of XRD data for LVO300 and LVO500 powders with reference pattern (PDF\#01-073-8145). $R_{w p}(L V O 300)=8.86 \%, R_{w p}(L V O 500)=11.34 \%$; (b) SEM image of LVO300; (c) SEM image of LVO500; (d) TEM image of LVO300; (e) TEM image of LVO500.

$\mathrm{Li}_{1.1} \mathrm{~V}_{3} \mathrm{O}_{8}$ material was synthesized via a sol-gel approach, adapted from a previous report. ${ }^{43} \mathrm{~V}_{2} \mathrm{O}_{5}$ and $\mathrm{LiOH} \cdot \mathrm{H}_{2} \mathrm{O}$ in stoichiometric ratio (Li: $\mathrm{V}=1.1: 3)$ were used as starting materials and stirred in aqueous solution at $50{ }^{\circ} \mathrm{C}$ under nitrogen atmosphere for $24 \mathrm{hrs}$. The solution was freeze-dried to remove water, and the precursor was annealed at either 300 or $500{ }^{\circ} \mathrm{C}$ to obtain the final products LVO300 and LVO500, respectively. To prepare the electrodes for galvanostatic cycling, LVO300 (or LVO500) were mixed with carbon, graphite and polyvinylidene fluoride (PVDF) in N-methyl-2-pyrrolidone (NMP) solution in a weight ratio of $85: 5: 5: 5$, followed by casting onto aluminum foil with $\sim 25 \mu \mathrm{m}$ thickness.

\section{Characterizations of LVO powder materials}

The elemental compositions of LVO300 and LVO500 powders were measured using a Thermo Scientific iCAP 6000 Inductively Coupled Plasma Optical Emission Spectrometer (ICP-OES). X-ray diffraction (XRD) of LVO300 and LVO500 powder materials was performed with a Rigaku Smartlab Diffractometer using $\mathrm{Cu} K \alpha$ radiation. Scanning electron microscope (SEM) images were were acquired using a JEOL 7600F Instrument. Transmission electron microscope (TEM) images were acquired using a JEOL $2100 \mathrm{~F}$ Instrument.

\section{Electrochemical discharge and EDXRD measurements}

To prepare the electrodes for EDXRD measurements, LVO300 (or LVO500) were mixed with carbon and graphite in a weight ratio of 90:5:5, and the solid mixtures were pressed into pellets of $\sim 500-600 \mu \mathrm{m}$ thickness. Coin type cells with LVO electrodes, $\mathrm{Li}$ metal anodes and polypropylene separators were constructed in an argon-filled glove box. $1 \mathrm{M} \mathrm{LiPF}_{6}$ in ethylene carbonate/dimethyl carbonate (volume ratio of 3:7) was used as electrolyte. The EDXRD measurement of LVO coin cells was conducted at the Advanced Photon Light Source at Argon National Laboratory on Beamline 6-BM-B. The experimental setup has been published previously. ${ }^{35}$ White beam radiation was focused with slits to make the final gauge volume $3.6 \times 0.1 \times 0.02 \mathrm{~mm}^{3}$. Coin cells were situated flat on the sample stage, which was moved vertically in $20 \mu \mathrm{m}$ increments to acquire the EDXRD spectrum for various regions inside the cell. The germanium energy detector was set to $2 \theta=3^{\circ}$. For operando measurements, LVO500 cell was discharged to $1.8 \mathrm{~V} \mathrm{vs}$. $\mathrm{Li} / \mathrm{Li}^{+}$charged at current rate of $\mathrm{C} / 18$ on a Maccor cycle life tester while the EDXRD spectra were collected. For in-situ measurements, LVO500 cells were predischarged at $\mathrm{C} / 40$ and $\mathrm{C} / 150$, respectively. And LVO300 cells were pre-discharged at $C / 18, C / 40$ and $C / 150$.

\section{Results and Discussion}

\section{Material characterizations}

The elemental compositions of LVO300 and LVO500 were confirmed to be $\mathrm{Li}_{1.1} \mathrm{~V}_{3} \mathrm{O}_{8}$ by ICP-OES. The XRD data of LVO300 and LVO500 could be indexed to the $\mathrm{Li}_{0.97} \mathrm{~V}_{3} \mathrm{O}_{8}$ reference pattern (PDF\#01-073-8145) with $P 2 \sqrt{ } / m$ space group. LVO500 showed stronger peak intensities with narrower full width at half maxima (FWHM) compared to LVO300, indicating higher crystallinity, consistent with the higher annealing temperature. Using the Scherrer equation, the crystallite size of LVO300 and LVO500 were estimated to be 26 and $69 \mathrm{~nm}$, respectively.

Table 1 Rietveld refinement results of LVO500 and LVO300 powders

\begin{tabular}{|c|c|c|}
\hline & LVO300 & LVO500 \\
\hline$A(\AA ̊)$ & 6.62 & 6.64 \\
\hline$B(\AA ̊)$ & 3.58 & 3.59 \\
\hline$C(\AA ̊)$ & 11.97 & 11.99 \\
\hline $\mathrm{B}\left({ }^{\circ}\right)$ & 107.83 & 107.80 \\
\hline
\end{tabular}



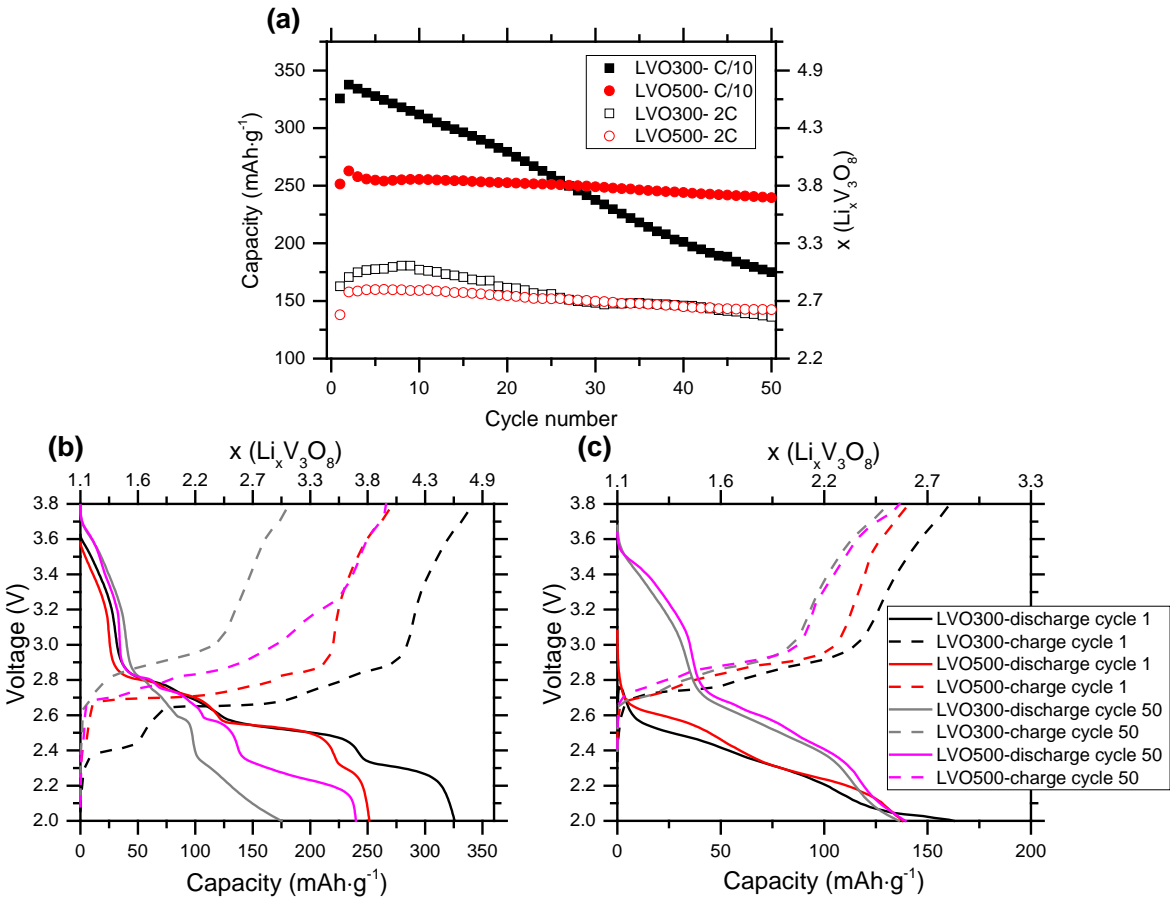

Figure 2 (a) Galvanostatic cycling of LVO300 and LVO500 coin cells at C/10 and 2C rate; (b) Voltage profile of cycle 1 and cycle 50 of LVO300 and LVO500 cell cycled at C/10; (c) Voltage profile of cycle 1 and cycle 50 of LVO300 and LVO500 cell cycled at $2 \mathrm{C}$

Rietveld refinement was performed on the XRD data, and as shown in Table 1, the lattice parameters of LVO300 and LVO500 are similar, and there are no significant differences in crystallographic structure between the two materials. SEM images (Figure $1 \mathbf{b}$ b-c) showed that LVO500 had a plate-like particle shape, while LVO300 was more porous without welldefined particle boundaries. According to TEM images, an individual LVO300 particle was much smaller than an individual LVO500 particle (Figure 1 d-e).

The data from galvanostatic cycling of lithium based two electrode cells containing LVO300 and LVO500 at C/10 and 2C is presented in Figure 2(a). Cycling at $\mathrm{C} / 10$, LVO300 showed higher initial capacity, reaching a $\mathrm{Li}$ content of $\mathrm{Li}_{4.6} \mathrm{~V}_{3} \mathrm{O}_{8}$ in the fully discharged state, however, the capacity decay was significant, with only $54 \%$ of the initial capacity remaining after 50 cycles. LVO500 exhibited an initial capacity of $251 \mathrm{mAh} \cdot \mathrm{g}^{-1}$, reaching $\mathrm{Li}_{3.8} \mathrm{~V}_{3} \mathrm{O}_{8}$ at the end of discharge, and $99 \%$ of the initial capacity was maintained after 50 cycles. As described previously, during discharge, the LVO structure maintains layered $\alpha$ phase until the lithiation state of $\sim \mathrm{Li}_{2.5} \mathrm{~V}_{3} \mathrm{O}_{8}$, when the $\alpha$ phase begins to transform into the defected rock-salt structure $\beta .^{34}$ Continued lithiation results in the formation of the pure $\beta$ phase by $\mathrm{Li}_{3.5} \mathrm{~V}_{3} \mathrm{O}_{8}-\mathrm{Li}_{4} \mathrm{~V}_{3} \mathrm{O}_{8}$. The discharge curves of LVO300 and LVO500 at C/10 are displayed in Figure 2(b). Compared with LVO500, the plateau at $\sim 2.6 \mathrm{~V}$ which is associated with the $\alpha-\beta$ transition was longer in LVO300 on cycle $1 .{ }^{34,44}$ Further, LVO300 showed a longer $\sim 2.3 \mathrm{~V}$ plateau than LVO500. The reaction at $\sim 2.3 \mathrm{~V}$ has been proposed to be associated with lithiation of the single $\beta$ phase and the formation of a more symmetric rock-salt structure. ${ }^{44} \mathrm{~A}$ prior in- situ XRD study on LVO showed single phase lithiation in a $\beta$ phase at $\sim 2.3 \mathrm{~V}^{34}$ This suggests that LVO300 gained more capacity through lithiation of the $\beta$ phase and thus underwent a comparably greater level of structural change. The curves of cycle 50 of both materials showed a shortened $2.6 \mathrm{~V}$ plateau, indicating the structural change associated with the $\alpha-\beta$ transition is a significant factor that results in capacity loss. Cycling at a higher $2 \mathrm{C}$ rate, the initial discharged compositions of LVO300 and LVO500 were $\mathrm{Li}_{2.8} \mathrm{~V}_{3} \mathrm{O}_{8}$ and $\mathrm{Li}_{2.6} \mathrm{~V}_{3} \mathrm{O}_{8}$, respectively. The capacity fade of $\mathrm{LVO} 300$ under $2 \mathrm{C}$ was not as significant as under $\mathrm{C} / 10$, and the fade was still worse than LVO500 cycled at the same rate. The LVO300 maintained 84\% of its initial capacity after 50 cycles, whereas LVO500 barely faded over 50 cycles. The better cyclic stability at higher rate could be attributed to the lower Li content in the discharged state which indicates that the materials go through comparably less structural transformation. This assertion is also supported by the voltage profiles in Figure 2(c), where the curves are more sloping under the $2 \mathrm{C}$ rate and no clear $\sim 2.6 \mathrm{~V}$ and $2.3 \mathrm{~V}$ plateaus can be found.

The cycling result is consistent with prior reports, ${ }^{24}$ and the higher initial capacity and poorer capacity retention of LVO300 compared to LVO500 can be related to the lower crystallinity resulting from the lower annealing temperature. The different cycling behaviors of LVO5OO and LVO300 motivated further structural investigation of electrodes discharged at different rates.

\section{Operando EDXRD of LVO500}




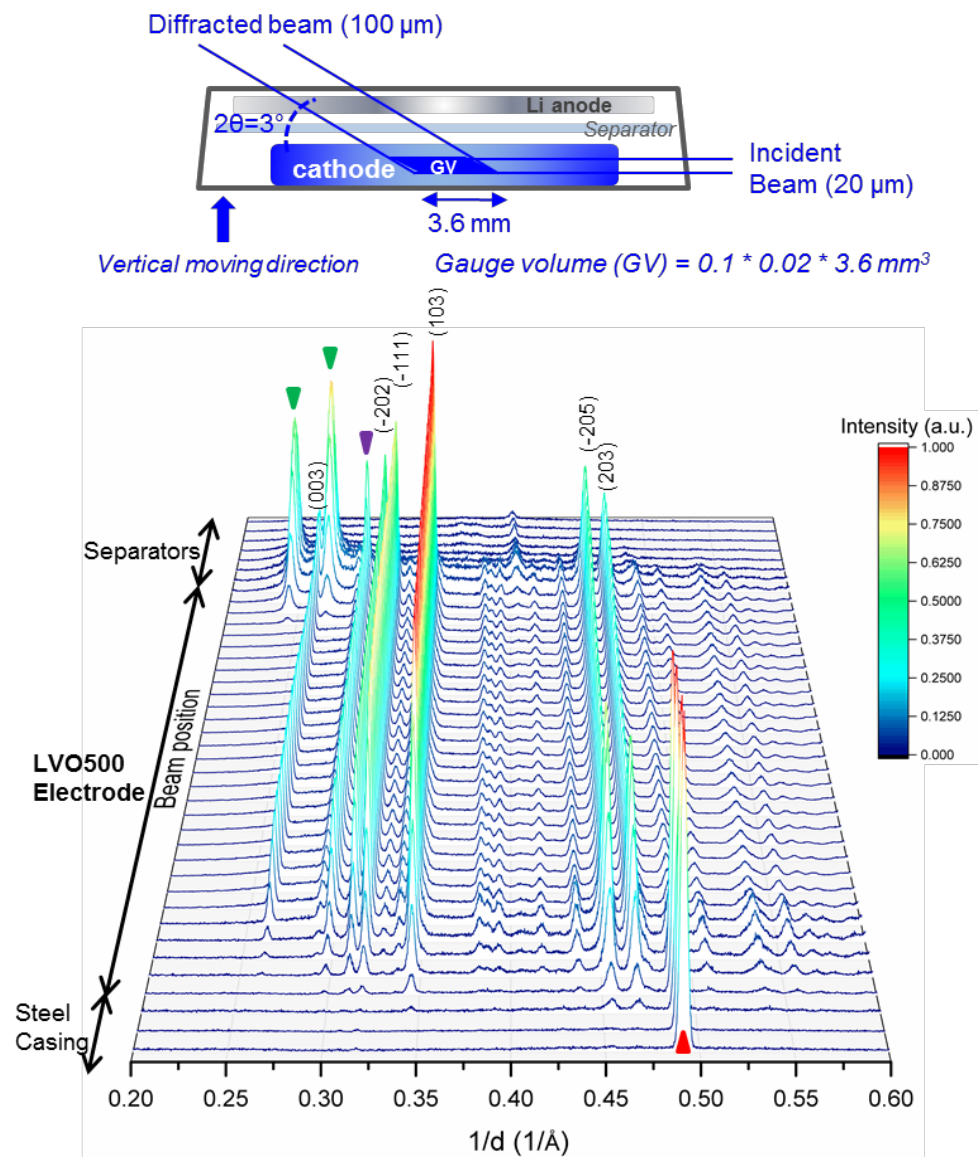

Figure 3 EDXRD experimental setup (top) and EDXRD patterns (bottom) with respect to the beam position of LVO500 coin cell. Peaks which are associated with polypropylene separators, graphite and stainless steel casing are indicated by green, purple and red triangles, respectively.

The full set of EDXRD patterns as a function of beam position for the LVO500 cell before discharge is shown in Figure 3. Diffraction patterns were collected in $20 \mu \mathrm{m}$ increments in the cell cathode. The peaks which are attributed to polypropylene separator, graphite and stainless steel casing are indicated in the figure. Major peaks of LVO are also indexed in the figure. The diffraction intensity of these peaks does not correlate with the intensity of the ADXRD diffraction pattern. In the EDXRD experiment, the peak intensities are also correlated with the energy flux from synchrotron radiation. Therefore, the flux of energy changes depending on the crystallographic plane that is being observed. As shown in Figure 3, the (103) peak is the most intense peak in EDXRD data of LVO500, with the $(-111)$ peak having the second highest intensity. For the LVO300 sample the (-111) was the most intense peak. This differs with the ADXRD pattern of LVO where (100) is the most intense peak.

The voltage profile of the LVO500 cell discharged and charged at $\mathrm{C} / 18$ for the operando EDXRD measurement is shown in Figure 4. $\mathrm{Li}_{1.1} \mathrm{~V}_{3} \mathrm{O}_{8}(\alpha)$ was lithiated to $\mathrm{Li}_{3.7} \mathrm{~V}_{3} \mathrm{O}_{8}(\beta)$ phase at the end of discharge, and de-lithiated to $\mathrm{Li}_{1.2} \mathrm{~V}_{3} \mathrm{O}_{8}(\alpha)$ phase at the end of charge. Colored contour plots were utilized to illustrate the phase transformation process and spatial phase distribution with respect to beam position. Contours of selected scans are shown, and corresponding discharge/charge periods are indicated on the voltage profile. Scan 1 was taken before the discharge started, and scan 20 was taken after the cell was charged to $3.8 \mathrm{~V}$.

From Scan 1 to Scan 4, the phase transition from the initial Lipoor $\alpha$ phase $\left(\mathrm{Li}_{1.1} \mathrm{~V}_{3} \mathrm{O}_{8}\right)$ to a distorted layered Li-rich $\alpha$ phase $\left(\mathrm{Li}_{2.5} \mathrm{~V}_{3} \mathrm{O}_{8}\right)$ occurred. The phase transition is indicated by the (202) peak at $1 / d=0.311 \AA^{-1}$ moving toward a higher inverse $d$ space (contracting) and the $(-111)$ peak at $1 / d=0.319 \AA^{-1}$ migrating to a lower inverse $d$ space (expanding) to accommodate Li ions. During the progression of the discharge, the area of the electrode near the lithium anode was more lithiated compared to the side of the electrode near the stainless steel can, providing strong evidence that the reaction front was initiated at the electrode interface near the lithium anode. The area of the cathode near the lithium anode is the Li-ion diffusion interface because it is near the area of highest $\mathrm{Li}^{+}$ion concentration in the cell during discharge, while the stainless steel can interface is the electron limited region of the cathode due to its contact with the current collector. Since all of the reaction fronts observed in this operando experiment are initiated at the lithium anode interface, the discharge is Liion diffusion limited and electronic access is fully percolated throughout the electrode. For example, in Scan 4 the $(-202)$ peak moved to $0.319 \AA^{-1}$ and $(-111)$ peak moved to $0.312 \AA^{-1}$ on the $\mathrm{Li}$ anode side of the electrode, while the $(-202)$ peak 

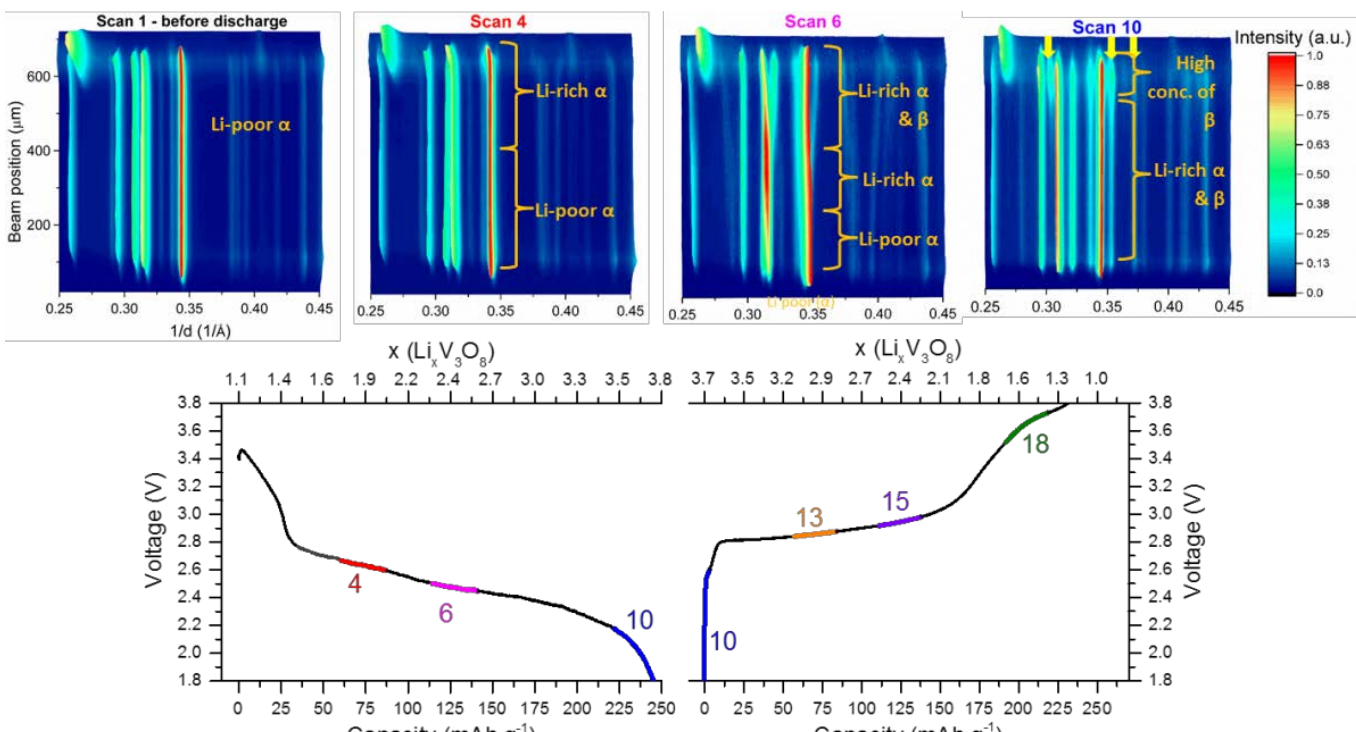
Capacity $\left(\mathrm{mAh} \cdot \mathrm{g}^{-1}\right)$
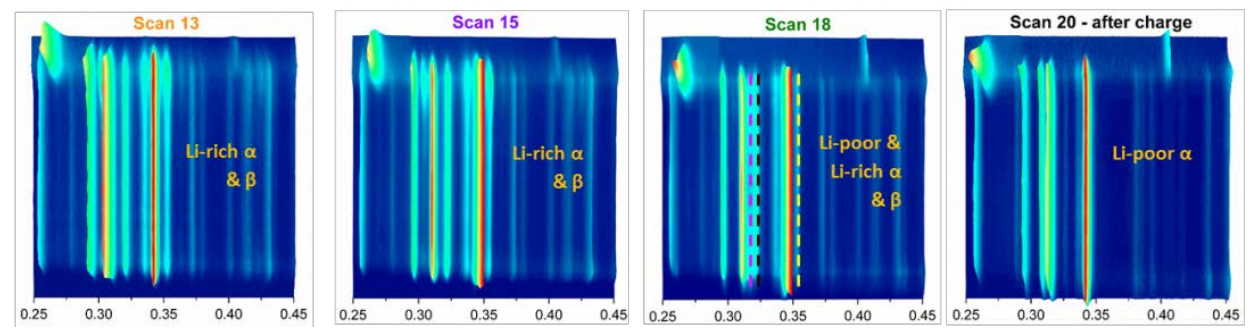

Figure 4 Discharge profile of LVO500 cell discharged and charged at C/18 for operando EDXRD measurements, and colored contour plots of the EDXRD spectra for selected scans with respect to beam position. The pink, black and yellow dash lines in the contour of Scan 18 highlights (-111) peak of Li-poor $\alpha,(-111)$ peak of Li-rich $\alpha$ and (103) peak of $\beta$, respectively.

was at $0.311 \AA^{-1}$ and $(-111)$ peak was at $0.316 \AA^{-1}$ at the stainless steel side. Similarly, the (103) peak moved from the original position of 0.346 to $0.341 \AA^{-1}$ on the Li anode side, and to $0.343 \AA^{-1}$ on the stainless steel side.

The (103) peak of $\beta$ phase $\left(\mathrm{Li}_{3.5} \mathrm{~V}_{3} \mathrm{O}_{8}-\mathrm{Li}_{4} \mathrm{~V}_{3} \mathrm{O}_{8}\right)$ at $0.349 \AA^{-1}$ emerged on the $\mathrm{Li}$ anode side at Scan 5 . The peak became more visible in Scan 6, and concurrently the $\alpha$ phase (103) peak started to split into two separate peaks at the $L i$ anode interface. From Scan 6 to Scan 9, as more Li intercalated, the $\beta$ (103) peak became more intense and gradually propagated throughout the electrode to the stainless steel interface. The $\beta$ phase (112) peak at $0.372 \AA^{-1}$ also appeared and propagated concurrently with the (103) peak. The lower intensity $\beta$ phase $(-111)$ peak had its highest observable intensity at the Li anode interface in Scan 9. At the end of discharge, the $\beta$ (103) and (112) peaks were present throughout the electrode and the $\beta$ (-111) peak extended $\sim 100 \mu \mathrm{m}$ in into the electrode, propagating from the $\mathrm{Li}$ anode interface. These $\beta$ phase peaks are indicated by yellow arrows on Scan 10 contour. Simultaneous to the evolution of $\beta$ phase, the transition from the Li-poor to Li-rich $\alpha$ phase also propagated through the electrode. The $\alpha$ phase (-202) peak shifted to higher $1 / \mathrm{d}$ space and the $\alpha$ phase $(-111)$ peak shifted to lower $1 / d$ space. On Scan 10 , the $\alpha$ phase $(-202)$ peak was at $0.322 \AA^{-1}$ and $\alpha$ phase $(-111)$ peak was at $0.311 \AA^{-1}$ throughout the entire electrode. Li-rich $\alpha$ and $\beta$ phases were distributed homogenously throughout the electrode with no phase localization observed at the end of discharge. This implies that the initial transformation of Li-poor to Li-rich $\alpha$ phase happens heterogeneously initiating at the $\mathrm{Li}$ anode side then propagating throughout the entire electrode. However, the $\beta$ phase begins to form at the $\mathrm{Li}$ anode interface before the complete transformation of Li-poor to Li-rich $\alpha$ phase $\beta$ propagates throughout the electrode. Once a specific area of the electrode is saturated by Li-rich $\alpha$ phase the $\beta$ phase will begin to propagate in that area, but will not displace the Li-rich $\alpha$ phase. Therefore, the final discharged state of the electrode is a relatively homogenous mixture of Li-rich $\alpha$ and $\beta$ phase with a slightly higher concentration of $\beta$ phase at the Li anode interface.

The de-lithiation mechanism upon charge was very different than the lithiation process observed upon discharge. The phase transition from Li-rich to Li-poor $\alpha$ phase and the disappearance of $\beta$ phase did not initiate until a high depth of charge (DOC) and took place simultaneously on Scan 19. The de-lithiation process did not show localized phases, suggesting that the material de-lithiated uniformly across the electrode and that Li-ion diffusion is fast enough for even de-lithiation at this rate, deviating from the discharge mechanism. Interestingly, on Scan 18 , the $(-111)$ peak associated with Lipoor $\alpha$ appeared at $0.317 \AA^{-1}$ before the peaks associated with Li-rich $\alpha$ and $\beta$ receded in intensity. During the period of Scan 
18, Li-poor and Li-rich $\alpha$ and $\beta$ phases coexisted throughout the electrode. Additional dashed lines in the Scan 18 contour were added to show the $(-111)$ peak of Li-poor $\alpha,(-111)$ peak of Li-rich $\alpha$, and (103) peak of $\beta$ phases represented by the pink, black, and yellow dashed line, respectively. The observed co-existence of three phases was never observed in prior studies, and implies that the transition from $\beta$ to $\alpha$ and from $\mathrm{Li}$ rich to Li-poor $\alpha$ phases was not a successive process during charge. The receding of $\beta$ (103) and (112) peaks and the transition from Li-rich to Li-poor $\alpha$ started on Scan 19 at the same time. At the end of charge, and the peak positions were identical to the starting $\alpha$ phase and no phase localizations were observed.

In a previous in-situ ADXRD study with LVO electrodes approximately $20 \mu \mathrm{m}$ thick and $13 \mathrm{~mm}$ in diameter cycled at $\mathrm{C} / 20$, the successive transformation from Li-poor to Li-rich $\alpha$ and from Li-rich $\alpha$ to $\beta$ was observed during discharge. ${ }^{31,34}$ The fully discharged bulk composition $\mathrm{Li}_{3.6} \mathrm{~V}_{3} \mathrm{O}_{8}$ was found to be the pure $\beta$ phase. During charge, the reverse phase transition process was observed, with $\beta$ to Li-rich $\alpha$ to Li-poor $\alpha$ phases occurring successively. In contrast, in this study operando EDXRD allowed the spatial phase distribution across the electrode to be assessed in real time using a pelletized LVO electrode, which was $\sim 20$ times thicker and $\sim 25$ times higher in mass loading than the electrode used for in-situ ADXRD study. The operando EDXRD technique provided more insight about how the phase transition process evolves spatially, with the battery deliberately constructed to emulate an energy dense system. In contrast to the previous ADXRD study, the operando measurements indicate that the phase transformation from Li-poor to Li-rich $\alpha$ phase and the formation of $\beta$ phase can proceed simultaneously in the electrode after the first formation of $\beta$ phase. The discharged state, $\mathrm{Li}_{3.7} \mathrm{~V}_{3} \mathrm{O}_{8}$ has mixed Li-rich $\alpha$ and $\beta$ phase distributed evenly across the electrode. Furthermore, the data indicates structural transformations occurring charging are not the reverse of those during discharge. The transformation from $\beta$ to Li-rich $\alpha$ and from Li-rich $\alpha$ to Li-poor $\alpha$ phases took place simultaneously at a high DOC. The formation of Li-poor $\alpha$ phase occurred before the total disappearance of $\beta$, and at a certain DOC Li-poor and Li-rich $\alpha$ and $\beta$ phases coexisted simultaneously.

\section{In-situ EDXRD of LVO300 and LVO500}

As discussed in previous sections, heat-treatment temperature has a strong influence on the cycling stability of the resulting LVO material. To better understand the difference in the lithiation process from a structural perspective, we examined the LVO500 and LVO300 cells pre-discharged at different rates, and compared the distribution and characteristics of (dis)charged phases.

The voltage profiles of the LVO500 and LVO300 cells discharged at $\mathrm{C} / 18, \mathrm{C} / 40$ and $\mathrm{C} / 150$ for the in-situ EDXRD

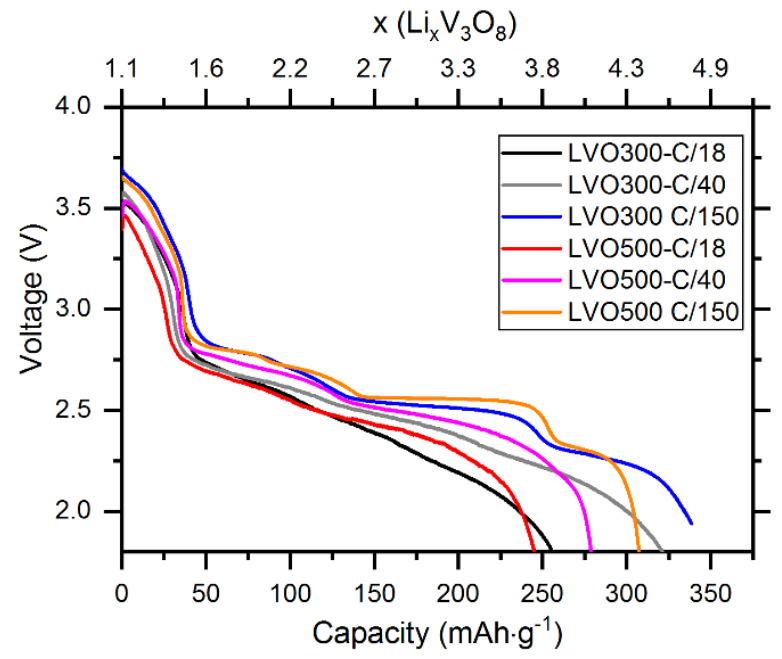

Figure 5 Voltage profiles of LVO500 and LVO300 cells discharged at C/18, C/40 and C/150 for EDXRD measurements.

measurement are presented in Figure 5. As reported previously, before the $\sim 2.6 \mathrm{~V}$ plateau, lithiation takes place in $\alpha$ phase, ${ }^{31,34}$ and the $\sim 2.6 \mathrm{~V}$ plateau marks the $\alpha-\beta$ transition process. After this transition, incoming $\mathrm{Li}$ intercalate in the single $\beta$ phase. At a slower rate of $C / 150$ clear discharge plateaus are observed as well as higher Li content at the end of discharge. At the same discharge rate, LVO300 demonstrated higher capacity and therefore higher Li content after discharge than LVO500, consistent with the previous finding that lower annealing temperature leads to higher initial capacity.

Mixed phases at C/18 EDXRD patterns of the LVO500 cell at fully discharged state of $\mathrm{Li}_{3.73} \mathrm{~V}_{3} \mathrm{O}_{8}$ (discharged to $1.8 \mathrm{~V}$, scan 10 in the operando experiment) were compared with the diffraction patterns of the LVO300 cell pre-discharged at C/18 to $1.8 \mathrm{~V}$ measured in-situ. From the discharge data shown in Figure 5, LVO500 and LVO300 had a similar composition at the end of discharge - $\mathrm{Li}_{3.73} \mathrm{~V}_{3} \mathrm{O}_{8}$ in $\mathrm{LVO500}$ and $\mathrm{Li}_{3.85} \mathrm{~V}_{3} \mathrm{O}_{8}$ in LVO300.

To compare the spatial distribution of $\alpha$ and $\beta$ phases in the fully discharged state for LVO300 and LVO500 cells, the position and intensity of selected $\alpha$ and $\beta$ peaks are shown in Figure 6. Both cells contained $\alpha$ and $\beta$ phases in the fully discharged state at $1.8 \mathrm{~V}$. As shown in Figure $\mathbf{6 a - b}$, the two phases in LVO500 were mixed evenly across the electrode, while in the LVO300 electrode, the $\beta$ phase was localized on the Li side, and the $\alpha$ phase was localized on the stainless steel can side of the electrode. As discussed previously in the operando LVO500 results, the Li-rich $\alpha$ and $\beta$ phases evolved concurrently after the first appearance of $\beta$, thus we observed mixed $\alpha$ and $\beta$ phases throughout the LVO500 electrode. Conversely, the LVO300 electrode has localized $\alpha$ and $\beta$ phases implying a successive transformation process from Li-poor to Li-rich $\alpha$, and from Li-rich $\alpha$ to $\beta$ phases at $\mathrm{C} / 18$. 

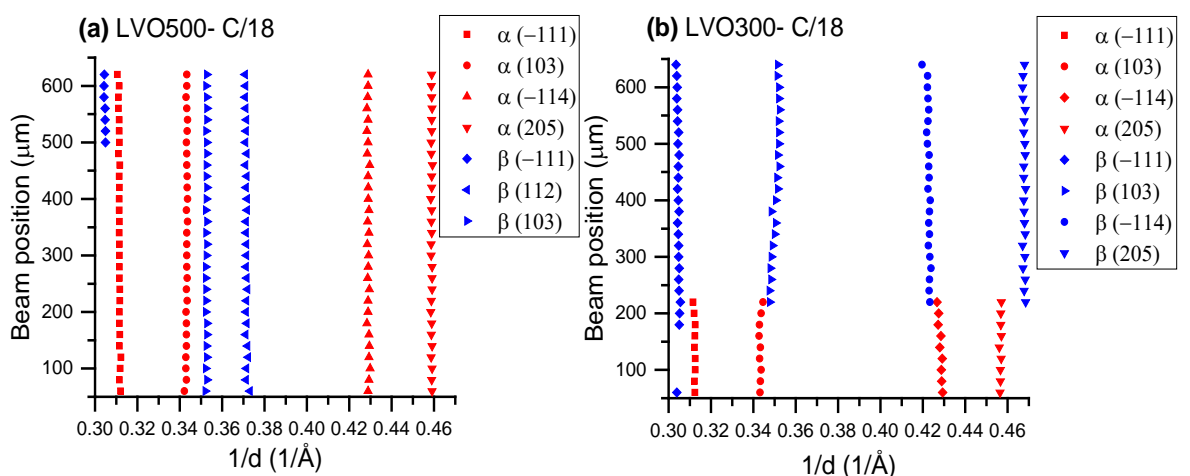

(c) LVO500- C/18
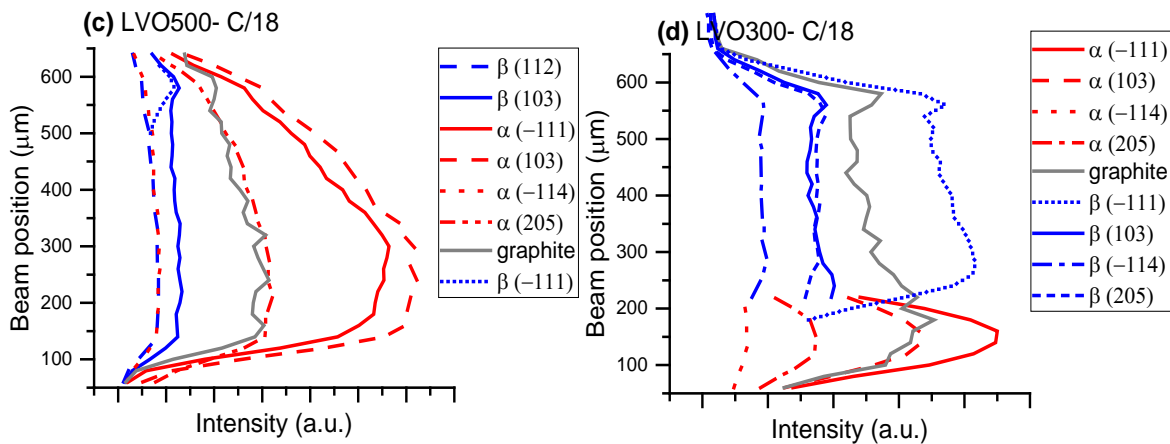

Figure 6 Peak position of $\alpha$ and $\beta$ as a function of beam position of (a) LVO500 cell discharged at $C / 18$ and (b) LVO300 cell discharged at C/18. And peak intensity of $\alpha$ and $\beta$ peaks and graphite (002) peak as a function of beam position of (c) LVO500 cell discharged at C/18 and (d) LVO300 cell discharged at C/18. Beam position $0 \mu \mathrm{m}$ is the stainless steel can.

Interestingly, the $\beta(-111)$ peak was also found on the stainless steel interface, as shown in Figure $\mathbf{6 b}$, indicating the transformation to $\beta$ could also initiate on the steel interface, and the stainless steel casing. This is the only observation of $\beta$ phase formation initiating at the electronic interface of the battery in all of the LVO electrode conditions.

In addition to the different phase distribution, the relative intensities of selected peaks of $\alpha$ and $\beta$ were compared in LVO500 and LVO300, Figure 6c-d. The graphite (002) peak at $0.297 \AA^{-1}$ was used as a reference to monitor the regions of varying intensity resulting from attenuation. As described previously, (103) was the strongest peak in the starting $\alpha$ structure of LVO500. In the fully discharged LVO500 electrode (Figure 6c), (103) peak was the most intense among the emerged $\beta$ peaks. Different from LVO500, in the starting $\alpha$ structure of LVO300, (-111) was the strongest peak, seconded by (103). And in the discharged LVO300 electrode (Figure 6d), $(-111)$ was more intense than other peaks where $\beta$ phase localized. The relative intensity of the $\beta$ phase peaks in the LVO500 and LVO300 electrodes discharged at $\mathrm{C} / 18$ is consistent with the starting $\alpha$ phase in each electrode.

Beta phase at $\mathrm{C} / 40$ and $\mathrm{C} / \mathbf{1 5 0}$ - EDXRD spectra of LVO500 and LVO300 discharged at C/40 (Figure 7a-b) and C/150 (Figure 7cd) measured in-situ were identified as homogeneous $\beta$ phase throughout the entire electrode for each cell. The relative intensities of major peaks are compared in Figure 7. Figure 7e displays the crystal structure of the $\beta$ phase with highlighted crystallographic planes (003), (103) and (-111). The $\beta(-111)$ peak was the most intense peak among the peaks observed in all four cells.

\section{Conclusions}

In this work, we investigated the phase transitions and phase localization in pelletized LVO electrodes using the energy dispersive $x$-ray diffraction (EDXRD) technique, which utilizes high-energy photons to record diffraction patterns as a function of spatial position in fully intact coin cell batteries. We performed operando electrode profiling during the de(lithiation) process of LVO500 cell at C/18, and identified the different stages of phase evolution. Several unique findings were enabled by the operando experiment. First, the lithiation reaction was found to initiate from the side of electrode facing the Li anode and subsequently proceed towards the side facing the steel can. Second, the transition from Li-poor to Li-rich $\alpha$ was found to continue after the formation of $\beta$ on the separator-LVO interface, indicating simultaneous rather than successive evolution of Li-rich $\alpha$ and $\beta$. The electrode had evenly mixed Li-rich $\alpha$ and $\beta$ at the end of discharge. Third, differing from prior reports, the operando data indicate that the structural evolution occurring charge is not the reverse of that during discharge. During charging, Li-poor $\alpha$ emerged before the disappearance of Li-rich $\alpha$ and $\beta$, and coexistence of three phases was observed for the first time. Peaks associated with Li-rich $\alpha$ and $\beta$ phases subsequently decreased in intensity simultaneously at a high depth of charge. 
(a) LVO500- C/40

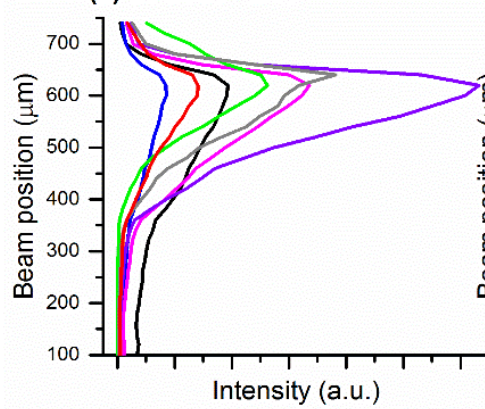

(c) LVO500- C/150

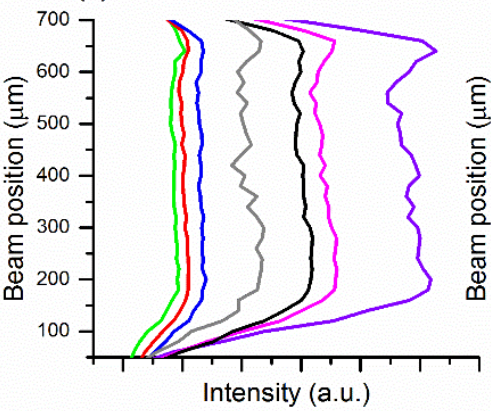

(b) LVO300- C/40

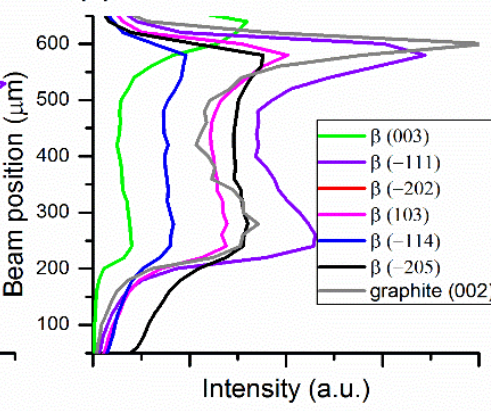

(d) LVO300- C/150

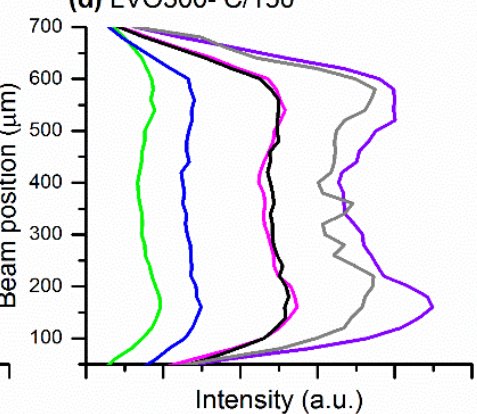

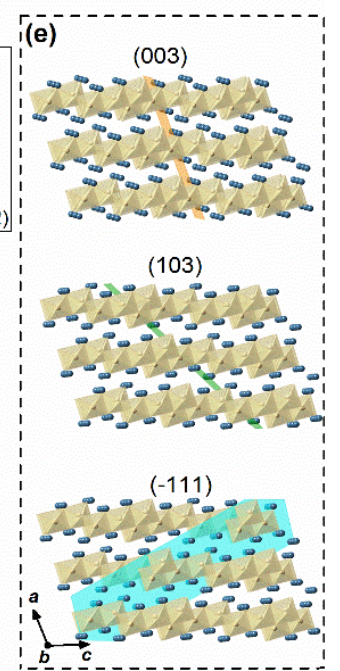

Figure 7 Peak intensity of $\beta$ and graphite (002) peak as a function of beam position of (a) LVO500 discharged at C/40, (b) LVO300 discharged at C/40 and (c) LVO500 discharged at $C / 150$ and (d) LVO300 discharge at $C / 150$, and (e) crystal structure of $\beta$ phase

In-situ EDXRD measurements on LVO500 and LVO300 predischarged at different rates were also performed to determine the influence of LVO crystallinity on the discharge process. Phase distribution and of relative intensity of peaks were compared after discharge to $1.8 \mathrm{~V}$ at $\mathrm{C} / 18, \mathrm{C} / 40$, and $\mathrm{C} / 150$ rates. In $\mathrm{C} / 18$ discharged electrodes, $\alpha$ and $\beta$ phases were mixed together in LVO500 electrode, while the two phases were separated and localized on two sides in the LVO300 electrode, indicating that the evolution of Li-rich $\alpha$ and $\beta$ was a successive process in LVO300 at this rate. Discharge at a current rate of $\mathrm{C} / 40$ and $\mathrm{C} / 150$ led to complete transformation to $\beta$ phase for both LVO500 and LVO300.

Thus, using operando and in-situ EDXRD measurements, we were able to achieve spatial resolution of the LVO electrode inside the battery cell during electrochemical process. The findings offer unique insight into the (de)lithiaition mechanism of LVO, providing the opportunity for continued development of the material for next-generation Li ion batteries.

\section{Acknowledgements}

This work was supported by Center for Mesoscale Transport Properties, an Energy Frontier Research Center supported by the U. S. Department of Energy, Office of Science, Basic Energy Sciences, under award \#DE-SC0012673. This research used resources of the Advanced Photon Source beamlines 6-BM, B and 10-BM, a U.S. Department of Energy (DOE) Office of Science User Facility operated for the DOE Office of Science by Argonne National Laboratory under Contract No. DE-ACO206CH113. Transmission electron microscopy experiments were performed using facilities at the Center for Functional Nanomaterials at Brookhaven National Laboratory, which was supported by DOE-BES User Facility Division, under contract \#DE-SC0012704 and the facilities in the Center for Materials, Devices and Integrated Systems (cMDIS) at Rensselaer Polytechnic Institute.

\section{Notes and references}

1. A. S. Tracey, G. R. Willsky and E. Takeuchi, Vanadium: Chemistry, Biochemistry, Pharmacology and Practical Applications, Taylor \& Francis, 2007.

2. J. S. Braithwaite, C. R. A. Catlow, J. D. Gale and J. H. Harding, Chemistry of Materials, 1999, 11, 1990-1998.

3. O. B. Chae, J. Kim, I. Park, H. Jeong, J. H. Ku, J. H. Ryu, K. Kang and S. M. Oh, Chemistry of Materials, 2014, 26, 5874-5881.

4. J. Dai, S. F. Y. Li, Z. Gao and K. S. Siow, Chemistry of Materials, 1999, 11, 30863090.

5. J. Dexmer, C. M. Leroy, L. Binet, V. Heresanu, P. Launois, N. Steunou, C. Coulon, J. Maquet, N. Brun, J. Livage and R. Backov, Chemistry of Materials, 2008, 20, 5541-5549.

6. A. Dobley, K. Ngala, S. Yang, P. Y. Zavalij and M. S. Whittingham, Chemistry of Materials, 2001, 13, 4382-4386.

7. Y. Makimura, L. S. Cahill, Y. Iriyama, G. R. Goward and L. F. Nazar, Chemistry of Materials, 2008, 20, 4240-4248.

8. S. Nordlinder, A. Augustsson, T. Schmitt, J. Guo, L. C. Duda, J. Nordgren, T. Gustafsson and K. Edström, Chemistry of Materials, 2003, 15, 3227-3232.

9. S. Nordlinder, L. Nyholm, T. Gustafsson and K. Edström, Chemistry of Materials, 2006, 18, 495-503.

10. E. S. Takeuchi, A. C. Marschilok, K. Tanzil, E. S. Kozarsky, S. Zhu and K. J. Takeuchi, Chemistry of Materials, 2009, 21, 4934-4939. 
11. D. Sun, G. Jin, H. Wang, P. Liu, Y. Ren, Y. Jiang, Y. Tang and X. Huang, Journal of Materials Chemistry A, 2014, 2, 12999-13005.

12. Y. Yang, L. Li, H. Fei, Z. Peng, G. Ruan and J. M. Tour, ACS Applied Materials \& Interfaces, 2014, 6, 9590-9594.

13. A. Marschilok, C. Y. Lee, A. Subramanian, K. J. Takeuchi and E. S. Takeuchi, Energy \& Environmental Science, 2011, 4, 2943-2951.

14. C.-Y. Lee, A. C. Marschilok, A. Subramanian, K. J. Takeuchi and E. S. Takeuchi, Physical Chemistry Chemical Physics, 2011, 13, 18047-18054.

15. S. Liang, J. Zhou, G. Fang, J. Liu, Y. Tang, X. Li and A. Pan, ACS Applied Materials \& Interfaces, 2013, 5, 8704-8709.

16. D. Sun, G. Jin, H. Wang, X. Huang, Y. Ren, J. Jiang, H. He and Y. Tang, Journal of Materials Chemistry A, 2014, 2, 8009-8016.

17. K. M. Abraham, J. L. Goldman and M. D. Dempsey, Journal of the Electrochemical Society, 1981, 128, 2493-2501.

18. G. Pistoia, S. Panero, M. Tocci, R. V. Moshtev and V. Manev, Solid State lonics, 1984, 13, 311-318.

19. Z.-K. Wang, J. Shu, Q.-C. Zhu, B.-Y. Cao, H. Chen, X.-Y. Wu, B. M. Bartlett, K.-X. Wang and J.-S. Chen, Journal of Power Sources, 2016, 307, 426-434.

20. G. Pistoia, M. Pasquali, M. Tocci, R. V. Moshtev and V. Maner, Journal of The Electrochemical Society, 1985, 132, 281-284.

21. X. Cao, L. Xie, H. Zhan and Y. Zhou, Materials Research Bulletin, 2009, 44, $472-$ 477.

22. S. Huang, X. L. Wang, Y. Lu, X. M. Jian, X. Y. Zhao, H. Tang, J. B. Cai, C. D. Gu and J. P. Tu, Journal of Alloys and Compounds, 2014, 584, 41-46.

23. H. Y. XU, H. Wang, Z. Q. Song, Y. W. Wang, H. Yan and M. Yoshimura, Electrochimica Acta, 2004, 49, 349-353.

24. J. XU, H. ZHANG, T. ZHANG, Q. PAN and Y. GUI, Influence of heat-treatment temperature on crystal structure, morphology and electrochemical properties of LiV[3]O[8] prepared by hydrothermal reaction, Elsevier, Kidlington, ROYAUME-UNI, 2009.

25. D. Wang, L. Cao, J. Huang and J. Wu, Ceramics International, 2013, 39, 37593764.

26. N. Tran, K. G. Bramnik, H. Hibst, J. Prölß, N. Mronga, M. Holzapfel, W. Scheifele and P. Novák, Journal of The Electrochemical Society, 2008, 155, A384-A389.

27. Q. Liu, H. Liu, X. Zhou, C. Cong and K. Zhang, Solid State lonics, 2005, 176, 1549-1554.

28. E. I. Gillette, N. Kim, G. W. Rubloff and S. B. Lee, Phys. Chem. Chem. Phys., 2016, 18, 30605-30611.

29. A. J. Pearse, E. Gillette, S. B. Lee and G. W. Rubloff, Phys. Chem. Chem. Phys. 2016, 18, 19093-19102.

30. J. Kawakita, Y. Katayama, T. Miura and T. Kishi, Solid State lonics, 1998, 107, 145-152.

31. S. Jouanneau, A. Verbaere and D. Guyomard, Journal of Solid State Chemistry, 2005, 178, 22-27.

32. L. A. de Picciotto, K. T. Adendorff, D. C. Liles and M. M. Thackeray, Solid State lonics, 1993, 62, 297-307.

33. S. Sarkar, A. Bhowmik, M. Dixit Bharadwaj and S. Mitra, Journal of The Electrochemical Society, 2014, 161, A14-A22.

34. Q. Zhang, A. B. Brady, C. J. Pelliccione, D. C. Bock, A. M. Bruck, J. Li, V. Sarbada, R. Hull, E. A. Stach, K. J. Takeuchi, E. S. Takeuchi, P. Liu and A. C. Marschilok, Chemistry of Materials, 2017, 29, 2364-2373.

35. K. C. Kirshenbaum, D. C. Bock, A. B. Brady, A. C. Marschilok, K. J. Takeuchi and E. S. Takeuchi, Physical Chemistry Chemical Physics, 2015, 17, 11204-11210.

36. K. C. Kirshenbaum, D. C. Bock, Z. Zhong, A. C. Marschilok, K. J. Takeuchi and E. S. Takeuchi, J. Mater. Chem. A, 2015, 3, 18027-18035.
37. J. W. Gallaway, M. Menard, B. Hertzberg, Z. Zhong, M. Croft, L. A. Sviridov, D. E. Turney, S. Banerjee, D. A. Steingart and C. K. Erdonmez, Journal of The Electrochemical Society, 2015, 162, A162-A168.

38. J. W. Gallaway, B. J. Hertzberg, Z. Zhong, M. Croft, D. E. Turney, G. G. Yadav, D. A. Steingart, C. K. Erdonmez and S. Banerjee, Journal of Power Sources, 2016, 321, 135-142.

39. F. C. Strobridge, B. Orvananos, M. Croft, H.-C. Yu, R. Robert, H. Liu, Z. Zhong, T. Connolley, M. Drakopoulos, K. Thornton and C. P. Grey, Chemistry of Materials, 2015, 27, 2374-2386.

40. W. A. Paxton, Z. Zhong and T. Tsakalakos, Journal of Power Sources, 2015, 275, 429-434.

41. G. Liang, M. Croft and Z. Zhong, ECS Transactions, 2013, 50, 293-304.

42. Q. Zhang, A. M. Bruck, D. C. Bock, J. Li, E. A. Stach, E. S. Takeuchi, K. J. Takeuchi and A. C. Marschilok, MRS Advances, 2017, DOI: 10.1557/adv.2017.54, 1-6.

43. A. C. Marschilok, C. P. Schaffer, K. J. Takeuchi and E. S. Takeuchi, Journal of Composite Materials, 2013, 47, 41-49.

44. S. Jouanneau, A. L. La Salle, A. Verbaere and D. Guyomard, Journal of the Electrochemical Society, 2005, 152, A1660-A1667. 